\title{
Concentration Level of Polycyclic Aromatic Hydrocarbons Emitted from Oud Incense: Al-Baha City, Southwest Saudi Arabia
}

Hiba Abdalla Mahgoub* and Nimir Ali Salih

${ }^{1}$ Department of Chemistry, Al-Baha University, Saudi Arabia

${ }^{2}$ Department of Physics, Al-Baha University, Saudi Arabia

\begin{abstract}
Burning incense often produces air pollutants that may represent a health risk for humans. The Polycyclic Aromatic Hydrocarbons (PAHs) were identified in Oud incense which is matter of great concern because nowadays, incense is used inside homes as well as in public places and its adverse health effect cannot be ignored. Our main objective was to assess the concentration of individual PAHs compound in the smoke of Oud incence. The PAHs concentrations were determined by using High Performance Liquid Chromatography (HPLC). All Oud samples were collected from local market of Al-Baha city southwest Saudi Arabia. The total mean concentration of PAHs in Oud samples was 2.79 $\mathrm{mg} / \mathrm{m}^{3}$ and the mean concentration of individual PAHs namely naphthalene, acenaphthene, acenaphthylene, fluorene, phenanthrene, anthracene, fluoranthene, pyrene, chrysene, benzo(a)anthracene, benzo(b)fluoranthene and benzo(a) pyrene was $0.10,0.26,1.22,0.12,1.06,0.02,0.32,0.26,0.03,0.10,0.08$ and $0.18 \mathrm{mg} / \mathrm{m}^{3}$ respectively. The highest values of total PAHs were 5.72 and $4.05 \mathrm{mg} / \mathrm{m}^{3}$ found in samples 5 and 7 respectively and the lowest total concentration of $1.25 \mathrm{mg} / \mathrm{m}^{3}$ was found in sample 3 . The dominant PAHs were acenaphthylene, fluorene, phenanthrene, fluoranthene and pyrene.
\end{abstract}

Keywords: Oud incense; PAHs; HPLC; Al-Baha City

\section{Introduction}

Polycyclic aromatic hydrocarbons (PAHs) are large group of organic compounds with two or more fused aromatic ring. These compounds are solids with low volatility at room temperature. They are relatively insoluble in water and most can be degraded to simpler substances. Regulatory agencies such as US environmental protection agency (EPA) and agency for toxic substances and disease registry (ATSDR) have defined maximum allowable level of PAHs in the environment due to their adverse health effect to human [1]. Exposure to PAHs can occur from different sources such as water, food and air [2-5]. Incense burning is associated with many culture and ceremonies in many countries. The incense materials are used to fragrant the environment and most of the people do not know that this fragrant may cause indoor air problems. Different carcinogenic substances have been detected in incense smoke [6-9]. The exposure to incense smoke have been found to make lung cancer, asthma, headache, nausea and allergic to skin and eyes [10-12]. One of the suggestions to prevent lung cancer in the community should include the reduction or minimization of exposures to indoor air pollutants [13]. Beside PAHs, incense burning was found to be the significant source of particulates, heavy metals and volatile organic compounds [14-17]. One of the most widely used incense in all Arab Gulf region is Oud (or Oudh) which have been used as a fragrant in home and all other traditional ceremonies. Other names for Oud are agarwood, jinkoh, agar and aguru. Active components available in oil extract from agarwood have been studied [18-20]. Our previous study [21] had prove the presence of PAHs in Oud incense, and our aim in this article was to determine the concentration level of each $\mathrm{PAH}$ present in seven different types of Oud incense widely used in Al-Baha city and compare it to the allowable PAHs level given by different environmental agencies.

\section{Materials and Methods}

\section{Oud samples selection}

Oud incense samples have been collected from local market of AlBaha city. Table 1 presents the trade names and country of origin of each Oud sample.

\begin{tabular}{|c|c|c|}
\hline Sample No & Trade name & Country of origin \\
\hline 1 & Oud 350 & Cambodia \\
\hline 2 & Oud 2002 & Cambodia \\
\hline 3 & Oud 1000 & Cambodia \\
\hline 4 & Oud 500 & Cambodia \\
\hline 5 & Oud super 2080 & India \\
\hline 6 & Oud ceufi malaki & India \\
\hline 7 & Kalmentan & India \\
\hline
\end{tabular}

Table 1: Trade names and country of origin of Oud samples.

\section{Sampling process}

As described in our previous studies [6,21], the burning test system consists of burning unit and sampling chamber. PAHs pollutants produced during oud burning flow directly into the sampling chamber (steel cylinder with an internal diameter of $10 \mathrm{~cm}$ and height of $100 \mathrm{~cm}$ ). High efficiency particulate air (HEPA) filtration system has been used to remove any particles from air before entering in to the test chamber. A known weight of Oud incense was placed in the combustion unit which was connected to the sampling chamber. The exit airflow rate was $4 \mathrm{~L} / \mathrm{min}$. A zefluor membrane filter ( $47 \mathrm{~mm}, 0.5 \mu \mathrm{m}$, P5PQ047, Pall, USA) with $47 \mathrm{~mm}$ in-line filter holder (stainless steel, 2220, Pall, USA) was used to collect PAHs for $20 \mathrm{~min}$. Each tested sample was analyzed three times to ensure representative samples. The membrane filter was soxhlet extracted with methylene chloride for $15 \mathrm{~h}$ before use.

\section{Extraction of PAHs}

The PAHs were extracted as follows: the filter was inserted into

${ }^{*}$ Corresponding author: Hiba Abdalla Mahgoub, Department of Chemistry, Al-Baha University, Saudi Arabia, Tel: 00966562098139; E-mail: hibaabdalla@yahoo.com

Received November 24, 2016; Accepted December 19, 2016; Published January 02, 2017

Citation: Mahgoub HA, Salih NA (2017) Concentration Level of Polycyclic Aromatic Hydrocarbons Emitted from Oud Incense: Al-Baha City, Southwest Saudi Arabia. Mod Chem Appl 5: 201. doi: 10.4172/2329-6798.1000201

Copyright: ( 2017 Mahgoub HA, et al. This is an open-access article distributed under the terms of the Creative Commons Attribution License, which permits unrestricted use, distribution, and reproduction in any medium, provided the original author and source are credited. 
a 50-ml brown sampling vial followed by extraction using $40 \mathrm{ml}$ dichloromethane (analytical grade, Aldrich Chemical Co. Ltd) in an ultrasonic bath for $15 \mathrm{~min}$. This extraction was repeated three times to ensure complete extraction. The resultant solutions were filtered through a pre-cleaned pasteur pipette filled with solvent-rinsed glass wool, dried with anhydrous $\mathrm{Na}_{2} \mathrm{SO}_{4}$ (12-60 mesh, analytical grade, Loba Chemie Pvt. Ltd), and concentrated by a rotary evaporator in a thermostatic bath at $35^{\circ} \mathrm{C}$. The final volume, about $2-3 \mathrm{ml}$, was further reduced to $1 \mathrm{~mL}$ under a gentle nitrogen flow.

\section{High Performance Liquid Chromatography (HPLC) analysis}

The test method used for quantification of PAHs was ISO 15753:2006 [22]. The PAHs extracts were analyzed by HPLC equipped with fluorescence detector. Analytical column PAH C18 $5 \mu \mathrm{m}(3.0 \times$ $250 \mathrm{~mm}$ ), solvent mixture A: acetonitrile and B: acetonitrile/ water (50:50) were used as a mobile phase at a flow rate of $0.6 \mathrm{ml} / \mathrm{min}$. Sample of $20 \mu \mathrm{L}$ was injected into the column through the sample loop. All data for quantification of the PAHs were obtained by applying the gradient elution program shown in Table 2 at a controlled oven temperature of $25^{\circ} \mathrm{C}$. The optimal wavelengths for excitation and emission were found by peak scanning (Table 3 ). The quantification of the PAHs was made by using standard solutions as follows: standard stock solution $(10 \mathrm{mg} / \mathrm{L})$, intermediate standard solution $(200 \mu \mathrm{g} / \mathrm{L}$ in acetonitrile), working standard solution $(50 \mu \mathrm{g} / \mathrm{L}$ in acetonitrile). The peaks were identified based on their retention times, emission, and excitation spectrum which comparable to the reference spectra (Figure 1). The mean recovery value of PAHs using this method was $70-110 \%$.

\section{Results and Discussion}

The PAHs found in the seven Oud incense samples were naphthalene, acenaphthene, acenaphthylene, fluorene, phenanthrene, anthracene, fluoranthene, pyrene, chrysene, benzo(a)anthracene, benzo(b)fluoranthene and benzo(a)pyrene. The total mean

\begin{tabular}{|c|c|c|}
\hline Time (min) & Solvent mixture A & Solvent mixture B \\
\hline 0 & 0 & 100 \\
\hline 5 & 0 & 100 \\
\hline 27 & 60 & 40 \\
\hline 36 & 100 & 0 \\
\hline 41 & 100 & 0 \\
\hline 43 & 0 & 100 \\
\hline 45 & 0 & 100 \\
\hline
\end{tabular}

Table 2: Gradient elution program on $\mathrm{C}_{18}$ column

\begin{tabular}{|c|c|c|c|}
\hline Detected Group & $\begin{array}{c}\text { Time } \\
\text { (min) }\end{array}$ & $\begin{array}{c}\text { Excitation } \\
\text { wavelength (nm) }\end{array}$ & $\begin{array}{c}\text { Emission wavelength } \\
\text { (nm) }\end{array}$ \\
\hline $\begin{array}{c}\text { Naphthalene } \\
\text { Acenaphthene } \\
\text { Fluorine }\end{array}$ & 0 & 270 & 324 \\
\hline $\begin{array}{c}\text { Phenanthrene } \\
\text { Anthracene }\end{array}$ & 12,6 & 248 & 357 \\
\hline $\begin{array}{c}\text { Fluoranthene } \\
\text { Pyrene }\end{array}$ & 16,4 & 280 & 462 \\
\hline $\begin{array}{c}\text { Benzo(a)anthracene } \\
\text { Chrysene }\end{array}$ & 18,05 & 270 & 385 \\
\hline $\begin{array}{c}\text { Benzo(b)fluoranthene } \\
\text { Benzo(k)fluoranthene } \\
\text { Benzo(a)pyrene } \\
\text { Dibenzo(a,h)anthracene } \\
\text { Benzo(g,h,i)perylene }\end{array}$ & 31,1 & 28 & 446 \\
\hline \begin{tabular}{c} 
Indeno(1,2,3-c,d)pyrene \\
\hline
\end{tabular} & 38 & 274 & 507 \\
\hline
\end{tabular}

Table 3: Programme of excitation and emission wavelength pairs. concentration of PAHs in Oud samples was found to be $2.79 \mathrm{mg} / \mathrm{m}^{3}$ and the mean concentration of individual PAHs namely naphthalene, acenaphthene, acenaphthylene, fluorene, phenanthrene, anthracene, fluoranthene, pyrene, chrysene, benzo(a)anthracene, benzo(b) fluoranthene and benzo(a)pyrene was $0.10,0.26,1.22,0.12,1.06$, $0.02,0.32,0.26,0.03,0.10,0.08$ and $0.18 \mathrm{mg} / \mathrm{m}^{3}$ respectively, shown in Table 4. The highest total concentrations of PAHs of 5.72 and 4.05 $\mathrm{mg} / \mathrm{m}^{3}$ were found in samples 5 and 7 respectively. The lowest total concentration of $1.25 \mathrm{mg} / \mathrm{m}^{3}$ was found in sample 3. The total PAHs concentration in Oud incense samples was higher than the allowable level given by different environmental agencies. The occupational safety and health administration (OSHA) permissible exposure level for PAHs in the workplace is $0.2 \mathrm{mg} / \mathrm{m}^{3}$ for 8 -hour workday [23]. The national institute for occupational safety and health (NIOSH) has recommended the workplace exposure limit for PAHs be set at the lowest detectable concentration which is $0.1 \mathrm{mg} / \mathrm{m}^{3}$ recommended exposure limit for a 10-hour workday [24]. The American conference of governmental industrial hygienists threshold limit value of PAHs is $0.2 \mathrm{mg} / \mathrm{m}^{3}$ recommended for a normal 8-hour workday [25]. Naphthalene was found in samples 4,6 and 7 with highest concentration of $0.24 \mathrm{mg} / \mathrm{m}^{3}$ in sample 7. The reference dose for oral exposure of naphthalene which reported by IRIC, EPA is $3 \times 10^{-3} \mathrm{mg} / \mathrm{m}^{3}$ [26]. benzo(a)anthracene, benzo(b)fluoranthene and benzo(a) pyrene were found in sample 1 and 4 . The highest concentration of benzo(a)pyrene $\left(0.21 \mathrm{mg} / \mathrm{m}^{3}\right)$ was found in sample 4 which exceed the allowable reported level. The target annual mean values of benzo(a)pyrene of 0.7 to $13 \times 10^{-7} \mathrm{mg} / \mathrm{m}^{3}$

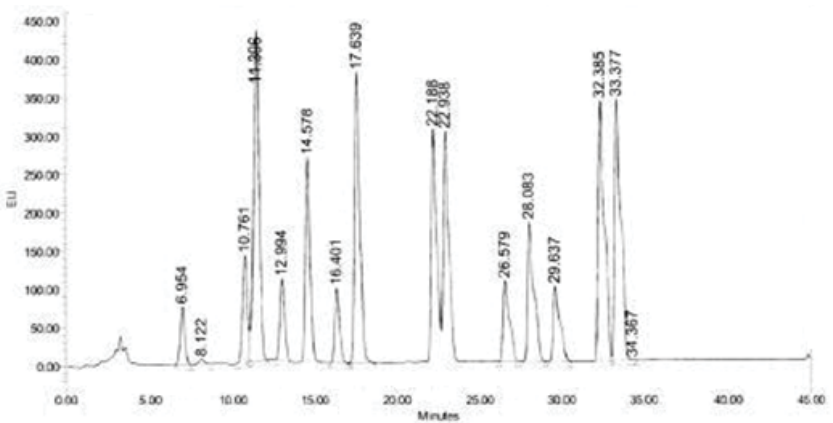

Figure 1: Typical chromatogram of PAHs standard mixture. Peaks: 1- Naphthalene 2- Acenaphthaylene, 3- Acenaphthene, 4- Flourene, 5- Phenanthrene, 6Anthracene, 7- Flouranthene, 8- Pyrene, 9-Benzo(a)anthracene, 10- Chrysene, 11- Benzo(b)fluoranthene, 12- benzo(k)flouranthene, 13- Benzo(a)pyrene, 14dibenzo(a,h)anthracene, 15- Benzo(g,h,i)perylene, 16- Indeno(1,2,3-cd)pyrene.

\begin{tabular}{|c|c|c|c|c|c|c|c|c|}
\hline PAHs & $\mathbf{1}$ & $\mathbf{2}$ & $\mathbf{3}$ & $\mathbf{4}$ & $\mathbf{5}$ & $\mathbf{6}$ & $\mathbf{7}$ & Mean \\
\hline Naphthalene & ND & ND & ND & 0.05 & ND & 0.02 & 0.24 & 0.10 \\
\hline Acenaphthene & 0.48 & - & - & - & - & - & 0.04 & 0.26 \\
\hline Acenaphathylene & ND & 1.04 & 0.58 & 0.36 & 3.13 & 1.02 & 1.18 & 1.22 \\
\hline Fluorene & 0.04 & - & - & 0.03 & 0.38 & 0.04 & - & 0.12 \\
\hline Phenanthrene & 0.37 & 0.87 & 0.67 & 0.18 & 2.21 & 0.82 & 2.32 & 1.06 \\
\hline Anthracene & 0.004 & - & - & 0.02 & - & 0.04 & - & 0.02 \\
\hline Fluoranthene & 0.24 & 0.56 & - & 0.18 & - & 0.33 & 0.27 & 0.32 \\
\hline $\begin{array}{c}\text { Pyrene } \\
\text { Chrysene }\end{array}$ & 0.09 & 0.38 & - & 0.23 & - & 0.35 & - & 0.26 \\
\hline $\begin{array}{c}\text { Benzo(a) } \\
\text { anthracene }\end{array}$ & 0.12 & - & - & 0.08 & - & - & - & 0.1 \\
\hline $\begin{array}{c}\text { Benzo(b) } \\
\text { fluoranthene }\end{array}$ & 0.06 & - & - & 0.09 & - & - & - & 0.08 \\
\hline Benzo(a)pyrene & 0.14 & - & - & 0.21 & - & - & - & 0.18 \\
\hline \begin{tabular}{c}
$\sum$ PAHs \\
\hline
\end{tabular} & 1.56 & 2.85 & 1.25 & 1.48 & 5.72 & 2.62 & 4.05 & 2.79 \\
\hline
\end{tabular}

Table 4: Concentration of PAHs $\left(\mathrm{mg} / \mathrm{m}^{3}\right)$ in Oud incense samples. 
established by European countries [27]. WHO recommended a health based guideline value of $1 \times 10^{-6} \mathrm{mg} / \mathrm{m}^{3}$ benzo(a)pyrene for ambient air [28] and a value of $1.1 \times 10^{-6} \mathrm{mg} / \mathrm{m}^{3}$ inhalation unit risk estimate calculated by California environmental protection agency [29]. In addition benzo(a)pyrene is often used as a marker for total exposure to carcinogenic PAHs as its contribution to the total carcinogenic potential is high [30].

\section{Conclusion}

The PAHs found in the seven Oud incense samples were naphthalene, acenaphthene, acenaphthylene, fluorene, phenanthrene, anthracene, fluoranthene, pyrene, chrysene, benzo(a)anthracene, benzo(b)fluoranthene and benzo(a)pyrene. The concentration of PAHs in the Oud incense samples was greater than the allowable level given by different environmental agencies. The total mean concentration of PAHs in Oud samples was found to be $2.79 \mathrm{mg} / \mathrm{m}^{3}$. The highest values of 5.72 and $4.05 \mathrm{mg} / \mathrm{m}^{3}$ were found in samples 5 and 7 respectively and the lowest total concentration of $1.25 \mathrm{mg} / \mathrm{m}^{3}$ was found in sample 3 . Burning incense is a common practice that companied with different ceremonies in many areas especially Middle east. Incense smoke remains throughout the day which increases duration of exposure to the toxic substances. Incense smoke as reported by many authors is one of the important indoor pollutants since it contains PAHs which have been classified as most pollutant compounds. The EPA (1994) has classified PAHs as a B-2 pollutant that means probable human carcinogen [31].

\section{Acknowledgements}

Financial fund of Al-Baha University, Ministry of Education, Saudi Arabia is acknowledged (Project No. 61-1436).

\section{References}

1. ATSDR Agency for Toxic Substances and Disease Registry (1995) Toxicological profile for polycyclic aromatic hydrocarbons. Atlanta GA, USA.

2. Fine PM, Cass GR, Simoneit BRT (2001) Chemical characterization of fine particle emissions from fireplace combustion of woods grown in the northeastern US. Environ sci technol 35: 2665-2675.

3. Hiba AM (2015) Polycyclic aromatic hydrocarbons in food samples methods of extraction A review. International journal of current research 7: 23603-23606.

4. Hiba AM (2015) Extraction techniques for determination of polycyclic aromatic hydrocarbons in water samples. International journal of science and research 5: 268-272.

5. Schauer JJ, Kleeman MJ, Cass GR, Simoneit BRT (2001) Measurement of emissions from air pollution sources $\mathrm{C}_{1}-\mathrm{C}_{29}$ organic compounds from fireplace combustion of wood. Environ sci technol 35: 1716-1728.

6. Hiba AM, Nimir AS (2015) Identification of polycyclic aromatic hydrocarbons emissions from wood of aromatic plants (Dokhan Incense) used in Sudan. Journal of chemistry and chemical sciences 5: 575-584.

7. Panida N, Manasawee A, Ohmar MTH (2008) Potential health effects of exposure to carcinogenic compounds in incense smoke in temple workers. Chemico-Biological interactions 173: 19-31.

8. Tzu TY, Shaw TL, Hsueh FH, Ruei HS, Jyun JW, et al. (2013) Effect of relative humidity on polycyclic aromatic hydrocarbon emissions from smoldering incense. Aerosol and air quality research 13: 662-671.

9. Tzu TY, Shaw TL, Tser SL, Wei LH (2011) Characterization of polycyclic aromatic hydrocarbon emissions in the particulate phase from burning incenses with various atomic hydrogen/carbon ratios. Science of total environment 414: 335-342.

10. Lin TCG, Swamy K, Chi DS (2008) Incense smoke: clinical, structural and molecular effects on airway disease. Clin Mol Allerg 6: 1-9.

11. Roveri P, Andrisano V, Pietra AMD, Cavrini V (1998) GC-MS analysis of incenses for possible presence of allergenic nitromusks. J Pharm Biomed Anal 17: 393-398
12. Chiang $\mathrm{KC}$, Chio $\mathrm{CP}$, Chiang $\mathrm{YH}$, Liao $\mathrm{CM}$ (2009) Assessing hazardous risks of human exposure to temple airborne polycyclic aromatic hydrocarbons. J Hazar Mater 166: 676-685

13. Lap AT, Ignatius TY, Hong Q, Joseph SKA, Xiao W (2011) A case referent study of lung cancer and incense smoke smoking and residential radon in Chinese men. Environ Health Perspect 119: 1641-1646.

14. Lin TC, Chang FH, Hsieh JH, Chao HR, Chao MR (2002) Characteristics of polycyclic aromatic hydrocarbons and total suspended particulate in indoor and outdoor atmosphere of a Taiwanese temple. J Hazard Mater 95: 1-12.

15. Fang GC, Chang CN, Chu CC, Wu YS, Fu PPC, et al. (2003) Fine (PM2.5) coarse (PM2.5-10) and metallic elements of suspended particulates for incense burning at Tzu Yun Yen temple in central Taiwan. Chemosphere 51: 983-991.

16. Yang HH, Jung RC, Wang YF, Hsieh LT (2005) Polycyclic aromatic hydrocarbon emissions from joss paper furnaces. Atm Environ 39: 3305-3312.

17. Werner T, Gaetano S (2015) Incense sparklers and cigarettes are significan contributors to indoor benzene and particle levels. Ann Super Sanita 51: 28-33.

18. Takemoto H, Ito M, Shiraki T, Yagura T, Honda G (2008) Sedative effects of vapor inhalation of agarwood oil and spikenard extract and identification of their active components. J Nat Med 62: 41-46.

19. Shimada Y, Konishi T, Kiyosawa S, Nishi M, Miyahara K, et al. (1986) Studies on the Agalwood (Jinko). IV: Structures of 2-(2-Phenylethyl)chromone Derivatives Agarotetrol and Isoagarotetrol. Chem Pharm Bull 34: 2766-2773.

20. Konishi T, Konoshima T, Shimada Y, Kiyosawa S (2002) Six new 2-(2-phenylethyl) chromones from Agarwood. Chem Pharm Bull 50: 419-422.

21. Hiba AM, Nimir AS, Tawfeeg EM (2015) Identification of polycyclic aromatic hydrocarbons emissions from Oud Incense-Al-Baha City Southwest Saudi Arabia. Int J Chem Sci Res 5: 12-22.

22. Ethiopian Standard (ES ISO 15753:2012) Animal vegetables fats and oilsDetermination of polycyclic aromatic hydrocarbons. 1st edn. Ethiopian Standards Agency.

23. Occupational Safety and Health Administration (1998) Occupational safety and health standards, toxic and hazardous substances. Code of federal regulations 29 .

24. National Institute for Occupational Safety and Health (NIOSH) (1997) Pocke Guide to Chemical Hazards. US Department of Health and Human Services, Public Health Service, Centers for Disease Control and Prevention. Cincinnati, $\mathrm{OH}$, USA.

25. Maynard RL (1999) 1999 TLVs and BEls: Threshold limit values for chemical substance and physical agents and biological exposure indices. Occup Environ Med 56: 791.

26. US Environmental Protection Agency (1999) Integrated Risk Information System (IRIS) on naphthalene. National Center for Environmental Assessment, Office of Research and Development, Washington, DC.

27. Ballesta PP, De Saeger E, Kotzias D (1999) State of the art of the PAHs' analysis in ambient air. Ispra, 22-24 March, 1999.

28. Boström CE, Gerde P, Hanberg A, Jernström B, Johansson C, et al. (2002) Cancer risk assessment, indicators, and guidelines for polycyclic aromatic hydrocarbons in the ambient air. Environ Health Perspect 110: 451-489.

29. California Environmental Protection Agency (1997) Air Toxics Hot Spots Program Risk Assessment Guidelines: Technical Support Document for Determining Cancer Potency Factors. Draft for Public Comment. Office of Environmental Health Hazard Assessment, Berkeley, CA.

30. Ohura T, Amagai T, Fusaya M, Matsushita H (2004) Polycyclic aromatic hydrocarbons in indoor and outdoor environments and factors affecting their concentrations. Environ Sci Technol 38: 77-83.

31. US Environmental Protection Agency (1994) Deposition of Air Pollutants to the Great Waters. First Report to Congress. EPA-453/R-93-055. Office of Air Quality Planning and Standards, Research Triangle Park, NC, USA 